\title{
SISTEM PAKAR FORWARD CHAINING, FUZZY-MAX DAN CERTAINTY FACTOR AYAM PEDAGING
}

\author{
Asep Afandi ${ }^{1}$, Dwi Marisa Efendi ${ }^{2}$ \\ ${ }^{1}$ Sistem Informasi, ${ }^{2}$ Teknologi Komputer , STMIK DIAN CIPTA CENDIKIA KOTABUMI \\ Jl. Raya Candimas No. 03, Lampung Utara - Indonesia 35418 \\ Telp. (0721) 787214 Fax. (0721) 700261 \\ e-mail: Asepafandi189@Gmail.Com,Dwimarisa89@Gmail.Com
}

\begin{abstract}
Chicken farming is one of the promising business potentials, but in management and care, it is very important to determine the success of chicken farming. Often in the care of negligent employees so that they are exposed to disease outbreaks. With various types of diseases that attack the symptoms are very similar and even the same as other diseases, therefore an expert system can be used to diagnose a disease by looking at the characteristics of the disease suffered, and how the solution is to treat or prevent the disease In the study, it discusses 8 types of broiler diseases, where the expert system method used is the Fuzzy Max method, Forward Chaining, and Certainty Factor. From the results of the Fuzzy Max method, the results showed an accuracy of $80 \%-90 \%$ for all types of diseases, while the Certainty Factor method showed 96\%-99\% for all types of diseases.
\end{abstract}

Keywords - Expert System, Fuzzy Max, Certainty Factor, Forward Chaining.

\section{ABSTRAKSI}

Peternakan ayam salah satu potensi bisnis yang menjanjikan, akan tetapi dalam manjemen, dan perawatan sangat menetukan keberhasilan peternakan ayam. Sering sekali dalam perawatan pegawai lalai sehingga terkena wabah penyakit. Dengan Berbagai Jenis penyakit yang menyerang gejalanya sangatlah mirip bahkan sama dengan penyakit lainya oleh karena itu sistem pakar dapat digunakan mendiagnosa suatu penyakit dengan melihat ciri-ciri penyakit yang diderita, dan bagaimana solusi dalam mengobati atau mencegah penyakit tersebut. Dalam penelitian memebahas tentang 8 jenis penyakit Broiler, dimana metode system pakar yang digunakan adalah metode Fuzzy Max, Forward Chaining, dan Certainty Factor. Dari hasil penelitian Metode Fuzzy Max diidapat hasil menunjukkan keakuratan 80\% - 90\% untuk semua jenis penyakit sedangkan metode Certainty Factor menunjukkan 96\%-99\% untuk semua jenis penyakit.

Kata Kunci-Sistem pakar , Fuzzy Max, Certainty Factor, Forward Chaining. 


\section{PENDAHULUAN}

Peternakan ayam salah satu potensi bisnis yang menjanjikan,akan tetapi dalam manjemen, dan perawatan sangat menetukan keberhasilan peternakan ayam. Sangat seing sekali dalam perawatan pegawai lalai sehingga terkena wabah penyakit. Dengan Berbagai Jenis penyakit yang menyerang gejalanya sangatlah mirip bahkan sama dengan penyakit lainggya oleh karena itu sistem pakar sangat dibutuhkan untuk mengetahui atau mendiagnosa suatu penyakit ayam pedaging dengan melihat ciri-ciri penyakit yang diderita dan solusi dalam mengobati atau mencegah penyakit tersebut. Dalam penelitian membahas 8 jenis penyakit ayam pedaging(Broiler), dimana metode system pakar yang digunakan adalah metode Fuzzy Max, Forward Chaining dan Certainty Factor.

Peneliti ini pengambilan data dibantu oleh seorang Petugas Penyuluh Lapangan dari PT. Ciomas Adisatwa cabang Lampung Tengah. Dimana data berupa data penyakit , gejala- gejala setiap penyakit dan obat - obatan didalamnya terdapat penjelasan tentang penyakit yang dapat disembuhkan, dan hal - hal pendukung lainnya. penulis menganalisa apa saja yang dibutuhkan oleh user dalam sistem yang akan dibangun.

\section{METODE PENELITIAN}

\subsection{Sistem Pakar}

Sistem Pakar adalah aplikasi komputer Artificial Intelligence (AI) yang berisi basis pengetahuan dan mesin inferensi sebagai komponen utama[1]. Expert System adalah sistem komputer yang meniru, atau bertindak dalam segala hal, dengan kemampuan pengambilan keputusan seorang pakar manusia. Komponen utamanya adalah: Basis pengetahuan, dapat diperoleh dari buku, majalah, orang berpengetahuan, dll. Mesin inferensi, menarik kesimpulan dari basis pengetahuan.[2]

\subsection{Forward Chaining}

Sistem pakar Forward chainning yang dapat membuat kesimpulan tentang fakta yang ada menggunakan aturan, objek dan mengambil tindakan yang sesuai sebagai hasilnya[1]. Forward Chaining penalaran yang dimulai dari sekumpulan data menuju kesimpulan[3]. 


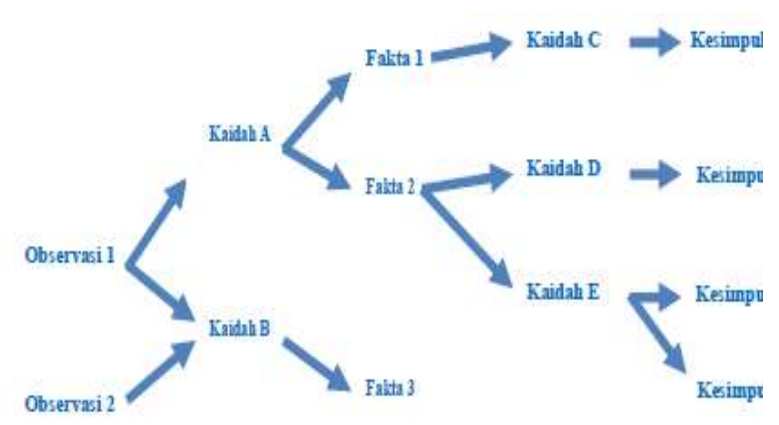

Gambar 1. Forward Chaining[3]

\subsection{Fuzzy Mamdani}

Bentuk distribusi yang memungkinan keluaran prosedur defuzzikasi cepat dan sederhana simple prosedurnya adalah mengambil salah satu nilai terbesar yang memiliki a derajat kebenaran maksimum (metode maxima)[4]. Pilihan yang mungkin adalah yang pertama (terkecil), yang terakhir (terbesar) atau, dalam kasus distribusi kemungkinan unimodal, nilai median. Sejauh ini metode maxima yang paling umum adalah memilih nilai ratarata elemen dengan derajat kebenaran maksimum (metode MOM)[4].

\subsection{Certainty Factor}

Metode Certainty Factor adalah pilihan yang tepat dalam penelitian ini, karena pada dasarnya metode $\mathrm{CF}$ diasumsikan sebagai tingkat kepercayaan pakar terhadap data yang digunakan. Metode Certainty Factor hanya dapat memproses dua bobot dalam satu perhitungan. Untuk bobot lebih dari 2 banyak, untuk melakukan perhitungan untuk menghindari masalah ketika bobot dihitung secara acak berarti tidak ada aturan untuk menggabungkan bobot karena kombinasi dari setiap hasil tersebut akan tetap sama. Penelitian sebelumnya menjelaskan hasil pencarian sistem pakar menunjukkan bahwa setiap gejala yang dipilih oleh pengguna akan dicari semua jenis penyakit yang memenuhi gejala tersebut[5]. Certainty Factor (CF) menunjukkan ukuran kepastian terhadap suatu fakta atau aturan. Metode faktor kepastian rumus umum sebagai berikut:

$$
\mathrm{CFs}[\mathrm{h}, \mathrm{e}]=\mathrm{MB}[\mathrm{h}, \mathrm{e}]-\mathrm{MD}[\mathrm{h}, \mathrm{e}]
$$

Keterangan:

$\mathrm{CFs}[\mathrm{h}, \mathrm{e}]=$ Faktor kepastian

$\mathrm{MB}[\mathrm{h}, \mathrm{e}]=$ Ukuran kepercayaan atau tingkat keyakinan terhadap hipotesis $\mathrm{h}$, jika diberikan evidence e (antara 0 dan 1)

$\mathrm{MD}[\mathrm{h}, \mathrm{e}]=$ Ukuran ketidakpercayaan atau tingkat keyakinan terhadap hipotesis $\mathrm{h}$, jika diberikan evidence e (antara 0 dan 1)

\subsection{Metode Penelitian}

Pada Peneltain ini menggnakan metode pengembanagan sistem Waterfall, dimana strategi pengembangan perangkat lunak pertama yang diterapkan, menyerupai desain yang digunakan di industri lain. Strategi ini memungkinkan projek dipecah 
menjadi beberapa fase[6]. Selain itu, dikenal sebagai siklus hidup klasik di mana metodologi ini adalah pendekatan siklus hidup paling dasar dan masih banyak digunakan dalam perangkat lunak. di bawah ini menunjukkan fase-fase pengembangan metodologi Waterfall [7].

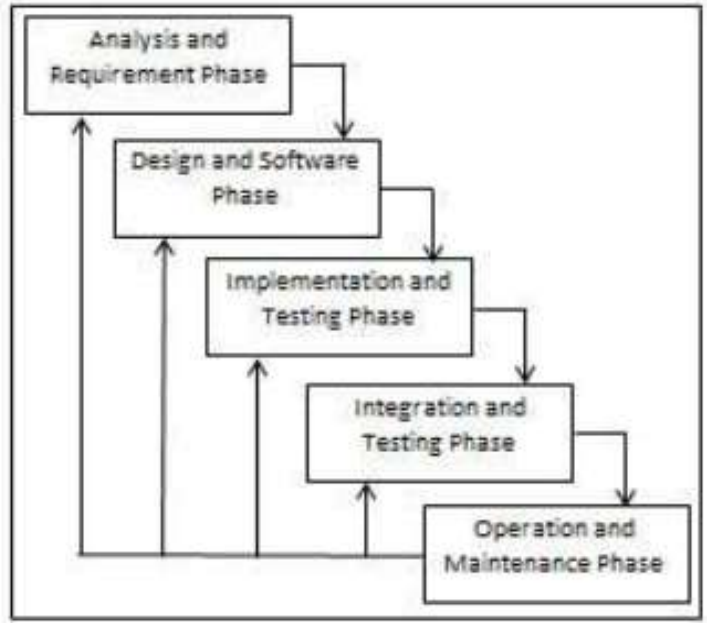

Gambar 2. Ilustrasi Model Waterfall [8]

\subsection{Knowledge Base}

Knowledge Base Berisakan fakta, aturan, dan objek. Sistem berbasis pengetahuan tujuannya adalah untuk menentukan aturan dalam format yang intuitif dan mudah dipahami, ditinjau, dan bahkan diedit oleh pakar domain seorang pakar TI.[4]

\section{Tabel 1. Penyakit Ayam Pedaging}

\begin{tabular}{|c|l|}
\hline $\begin{array}{c}\text { Kode } \\
\text { Penyakit }\end{array}$ & Nama Penyakit \\
\hline P1 & $\begin{array}{l}\text { Chronic Respiratory Disease } \\
\text { (CDR )( Ngorok) }\end{array}$ \\
\hline P2 & Pullorum Disease(Berak Kapur) \\
\hline P3 & Gumboro Disease(Gumboro) \\
\hline P4 & Newcastle Disease(Tetelo) \\
\hline P5 & Infectious Coryza(Snot) \\
\hline P6 & Fowl Typhoid(Tifus Ayam) \\
\hline P7 & Coccidosis(Berak Darah) \\
\hline P8 & Fowl kolera(penyakit kolera) \\
\hline
\end{tabular}

Tabel 2. Gejala

\begin{tabular}{|c|l|}
\hline $\begin{array}{c}\text { Kode } \\
\text { Gejala }\end{array}$ & \multicolumn{1}{|c|}{ Nama Gejala } \\
\hline 1 & Mata terpejam seperti mengantuk \\
\hline 2 & Keluar cairan berbusa dari mata \\
\hline 3 & Jengger membengkak merah \\
\hline 4 & Keluar nanah dari mata dan bau \\
\hline 5 & keseimbangan tubuhnya terganggu \\
\hline 6 & Sayap menggantung dan kusam \\
\hline 7 & $\begin{array}{l}\text { Terdapat kotoran putih menempel disekitas } \\
\text { anus }\end{array}$ \\
\hline 8 & Sayap terkulai \\
\hline 9 & Tidur paruhnya diletakan dilantai \\
\hline 10 & Duduk dengan sikap membungkuk \\
\hline
\end{tabular}

Tabel 3. Rules

\begin{tabular}{|c|c|c|c|c|c|c|c|c|}
\hline \multirow{3}{*}{$\begin{array}{l}\text { Kode } \\
\text { Gejala }\end{array}$} & \multicolumn{8}{|c|}{ Kode Penyakit } \\
\hline & $\mathrm{P}$ & $\mathrm{P}$ & $\mathrm{P}$ & $\mathrm{P}$ & $\mathrm{P}$ & $\mathrm{P}$ & $\mathrm{P}$ & \\
\hline & 1 & 2 & 3 & 4 & 5 & 6 & 7 & 8 \\
\hline 01 & & & & & & $\mathrm{v}$ & & $\mathrm{v}$ \\
\hline 02 & & & & $\mathrm{v}$ & $\mathrm{V}$ & & & $\mathrm{V}$ \\
\hline 03 & & & & $\mathrm{v}$ & $\mathrm{v}$ & & & \\
\hline 04 & & & $\mathrm{v}$ & & & & & \\
\hline 05 & & $\mathrm{v}$ & & & & & & \\
\hline 06 & $\mathrm{v}$ & & & & & & & \\
\hline 07 & $\mathrm{v}$ & & & & & & & \\
\hline 08 & & & & & & & & \\
\hline 09 & $\mathrm{v}$ & & & $\mathrm{v}$ & $\mathrm{V}$ & & $\mathrm{v}$ & \\
\hline 10 & & $\mathrm{v}$ & $\mathrm{V}$ & & & & & $\mathrm{v}$ \\
\hline 11 & $\mathrm{v}$ & & & & & & & \\
\hline 12 & & & & & & & & $\mathrm{v}$ \\
\hline 13 & & & & $\mathrm{v}$ & & & & \\
\hline 14 & & & & $\mathrm{v}$ & & & & \\
\hline 15 & & & & $\mathrm{v}$ & & & & $\mathrm{v}$ \\
\hline 16 & & & & & & $\mathrm{v}$ & & \\
\hline 17 & & & & & & & $\mathrm{v}$ & \\
\hline 18 & & $\mathrm{v}$ & & & & & & \\
\hline 19 & & & & & & & $\mathrm{v}$ & \\
\hline 20 & & & $\mathrm{~V}$ & & & & & \\
\hline
\end{tabular}




\subsection{Forward Chaining}

Lapangan, PT. Ciomas Adisatwa,

Lampung Tengah) maka didapat data

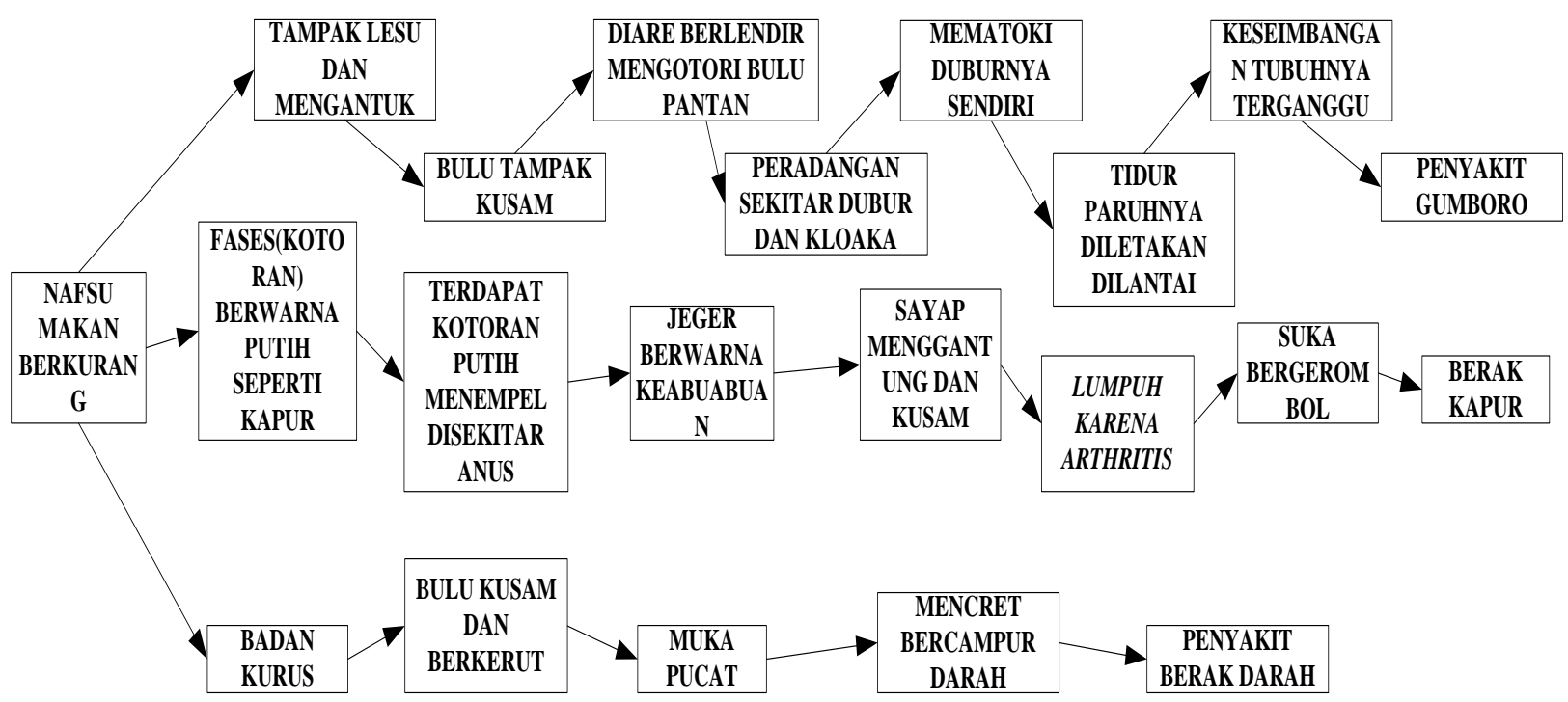

Gambar 3. Diagram Forward Chaining

Penyakit Gumboro, Penyakit Berak Kapur, dan Penyakit Berak Darah.

\subsection{Interpretasi Nilai Bobot}

Jawaban pengguna terhadap pertanyaan diagnosis yang akan diolah menjadi sebuah nilai CF . Dari CF tersebut akan dihitung nilai CF Rule Gejala dan Penyakit dinamakan proses konversi sebuah nilai. Dibawah ini merupakan nilai evidence yang ditentukan oleh pakar[9].

\section{Tabel 4. Nilai Bobot}

\begin{tabular}{|l|l|}
\hline Istilah & Bobot \\
\hline Kurang Berpengaruh & $0,1 \mathrm{~s} / \mathrm{d} 0,4$ \\
\hline Berpengaruh & $0,5 \mathrm{~s} / \mathrm{d} 0,7$ \\
\hline Sangat Berpengaruh & $0,8 \mathrm{~s} / \mathrm{d} 1,0$ \\
\hline
\end{tabular}

Dari hasil Interview dan Observasi dengan seorang Pakar (Petugas Penyuluh seperti Tabel 5 dibawah ini:

Table 5. Iterpretasi Nilai Bobot

\begin{tabular}{|c|c|c|c|}
\hline $\begin{array}{l}\text { Nama } \\
\text { Penya- } \\
\text { kit }\end{array}$ & Nama Gejala (Kode Gejala) & $\begin{array}{l}\text { Inter- } \\
\text { pretasi }\end{array}$ & $\begin{array}{l}\text { Bo- } \\
\text { bot }\end{array}$ \\
\hline \multirow{7}{*}{$\begin{array}{l}\text { Berak } \\
\text { Kapur } \\
\text { (Pullo- } \\
\text { rum } \\
\text { Dis- } \\
\text { ease) }\end{array}$} & Napsu makan menurun (09) & $\begin{array}{l}\text { Kurang } \\
\text { ber- } \\
\text { pengaru } \\
\text { h }\end{array}$ & 0,3 \\
\hline & $\begin{array}{l}\text { Feses (kotoran) berwarna } \\
\text { putih seperti kapur ( } 31)\end{array}$ & $\begin{array}{l}\text { Ber- } \\
\text { pengaru } \\
\text { h }\end{array}$ & 0,7 \\
\hline & $\begin{array}{llr}\text { Terdapat kotoran } & \text { putih } \\
\text { menempel } & \text { disekitar anus } \\
(37) & & \end{array}$ & $\begin{array}{l}\text { San- } \\
\text { gat ber- } \\
\text { pengaru } \\
\mathrm{h}\end{array}$ & 0,8 \\
\hline & $\begin{array}{l}\text { Jengger berwarna keabuan } \\
\text { (48) }\end{array}$ & $\begin{array}{l}\text { Ber- } \\
\text { pengaru } \\
\mathrm{h}\end{array}$ & 0,6 \\
\hline & $\begin{array}{l}\text { Sayap menggantung dan } \\
\text { kusam (06) }\end{array}$ & $\begin{array}{l}\text { Kurang } \\
\text { ber- } \\
\text { pengaru } \\
\text { h }\end{array}$ & 0,3 \\
\hline & $\begin{array}{l}\text { Lumpuh karena arthritis } \\
\text { (peradangan persendian) } \\
(18)\end{array}$ & $\begin{array}{l}\text { Ber- } \\
\text { pengaru } \\
\mathrm{h}\end{array}$ & 0,5 \\
\hline & Suka bergerombol (23) & $\begin{array}{l}\text { Kurang } \\
\text { ber- } \\
\text { pengaru } \\
\text { h }\end{array}$ & 0,4 \\
\hline
\end{tabular}




\begin{tabular}{|c|c|c|c|}
\hline \multirow{8}{*}{$\begin{array}{l}\text { Gumbo- } \\
\text { bo- } \\
\text { ro(Gum } \\
\text { boro } \\
\text { Dis- } \\
\text { ease })\end{array}$} & $\begin{array}{l}\text { Nafsu makan berkurang } \\
(09)\end{array}$ & $\begin{array}{l}\text { Kurang } \\
\text { ber- } \\
\text { pengaru } \\
\text { h }\end{array}$ & 0,3 \\
\hline & $\begin{array}{l}\text { Ayam tampak lesu dan } \\
\text { mengantuk (04) }\end{array}$ & $\begin{array}{l}\text { Kurang } \\
\text { ber- } \\
\text { pengaru } \\
\text { h }\end{array}$ & 0,3 \\
\hline & Bulu tampak kusam (20) & $\begin{array}{l}\text { Kurang } \\
\text { ber- } \\
\text { pengaru } \\
\text { h }\end{array}$ & 0,3 \\
\hline & $\begin{array}{l}\text { Diare berlendir yang men- } \\
\text { gotori bulu pantat }(26)\end{array}$ & $\begin{array}{l}\text { Ber- } \\
\text { pengaru } \\
\mathrm{h}\end{array}$ & 0,5 \\
\hline & $\begin{array}{l}\text { Peradangan di sekitar dubur } \\
\text { dan kloaka (33) }\end{array}$ & $\begin{array}{l}\text { Sangat } \\
\text { ber- } \\
\text { pengaru } \\
\mathrm{h}\end{array}$ & 0,8 \\
\hline & $\begin{array}{l}\text { Mematoki duburnya sendiri } \\
\text { (34) }\end{array}$ & $\begin{array}{l}\text { Ber- } \\
\text { pengaru } \\
\text { h }\end{array}$ & 0,6 \\
\hline & $\begin{array}{l}\text { Tidur paruhnya diletakan di } \\
\text { lantai (39) }\end{array}$ & $\begin{array}{l}\text { Ber- } \\
\text { pengaru } \\
\text { h }\end{array}$ & 0,5 \\
\hline & $\begin{array}{l}\text { Keseimbangan tubuhnya } \\
\text { terganggu (35) }\end{array}$ & $\begin{array}{l}\text { Ber- } \\
\text { pengaru } \\
\mathrm{h}\end{array}$ & 0,5 \\
\hline \multirow{5}{*}{$\begin{array}{l}\text { Berak } \\
\text { Darah( } \\
\text { Coc- } \\
\text { cidosis) }\end{array}$} & $\begin{array}{l}\text { Nafsu makan berkurang } \\
(09)\end{array}$ & $\begin{array}{l}\text { Kurang } \\
\text { ber- } \\
\text { pengaru } \\
\text { h } \\
\end{array}$ & 0,3 \\
\hline & Badan kurus (07) & $\begin{array}{l}\text { Kurang } \\
\text { ber- } \\
\text { pengaru } \\
\mathrm{h} \\
\end{array}$ & 0,3 \\
\hline & $\begin{array}{l}\text { Bulu kusam dan berkerut } \\
\text { (08) }\end{array}$ & $\begin{array}{l}\text { Ber- } \\
\text { pengaru } \\
\mathrm{h}\end{array}$ & 0,5 \\
\hline & Muka pucat (19) & $\begin{array}{l}\text { Ber- } \\
\text { pengaru } \\
\mathrm{h}\end{array}$ & 0,5 \\
\hline & $\begin{array}{l}\text { Mencret bercampur darah } \\
\text { (17) }\end{array}$ & $\begin{array}{l}\text { Sangat } \\
\text { ber- } \\
\text { pengaru } \\
\text { h }\end{array}$ & 0,9 \\
\hline
\end{tabular}

\subsection{Certainty Factor}

Berdasarkan data dari tabel 7 didapat

\section{$\underline{\text { Penyakit Berak Darah : }}$}

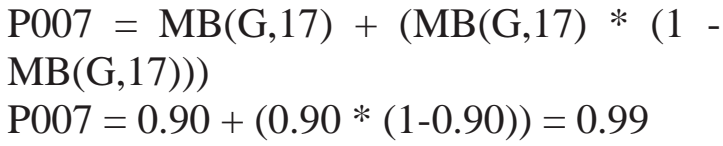

\subsection{Fuzzy Mamdani Max}

1. Penyakit Berak Darah (Coccidosis)

Berdasarkan data dari table 7 maka didapat seperti gambar grafik 4 dibawah ini:

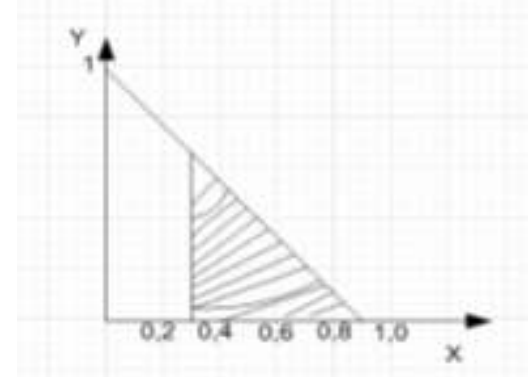

\section{Gambar 4. Grafik Penyakit Berak Darah}

Berdasarkan Data dari Gambar maka didapat:

$$
\begin{aligned}
\mu \mathrm{df}(\mathrm{xi})=\operatorname{Max} & (\mu \mathrm{df}(\mathrm{xi},) \mu \mathrm{kf}(\mathrm{xi})) \\
& =\operatorname{Max}(0,5 ; 0,9) \\
& =\operatorname{Max}(0,9)
\end{aligned}
$$

\subsection{Perancangan Sistem Pakar}

\subsubsection{Database}

Pada tahapan ini menjelaskan bagaimana proses terbentuknya suatu database, yang terdiri dari Entity Relationship Diagram (ERD), Class Diagram, dan Struktur Basis Data. 


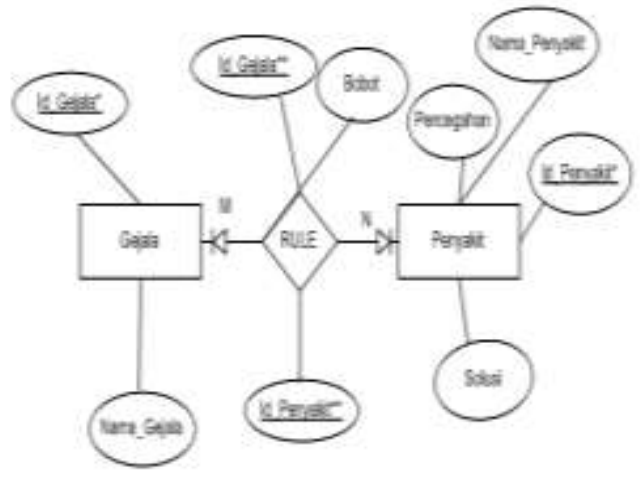

Gambar 5. Entity Relationship Diagram

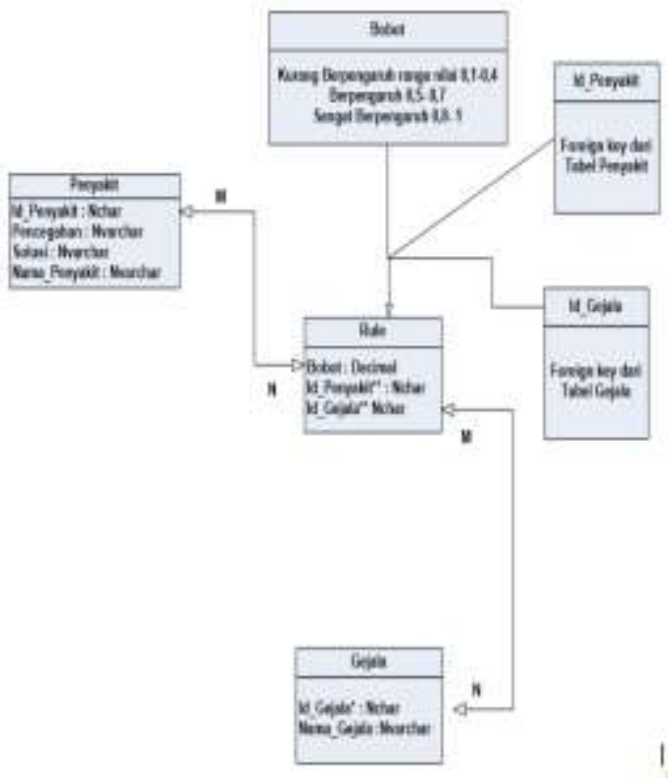

Gambar 6. Class Diagram

Class diagram struktur aplikasi detail untuk database.

\section{III.Hasil dan pembahasan}

Dari uraian pada metode penelitian bahwa bobot gejala yang nilainya diatas 0,6 dijadikan Gejala Primary dan Scondary dimana nilai bobot kedua terbesar untuk metode Certainty Factor sedangkan nilai yang paling besar sebagai nilai maksimumakan dijadikan nilai banding dengan rata-rata untuk metode Fuzzy Max yang diterapkan dalam aplikasi sistem pakar sehingga didapat:

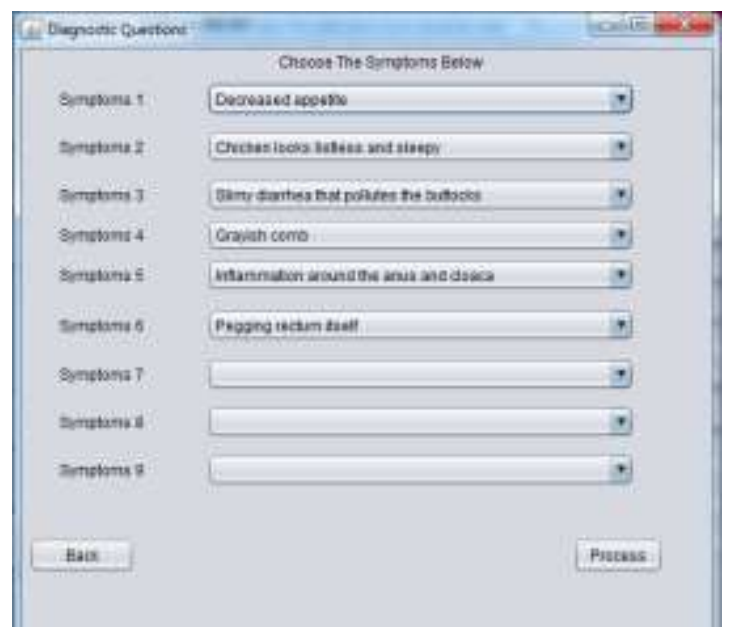

Gambar 7. Pemilihan Gejala Pada Pertanyaan Diagnosa.

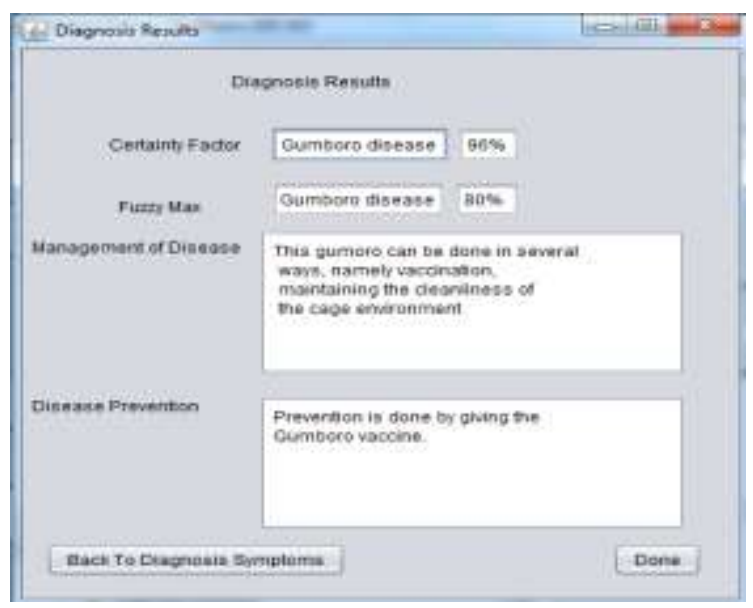

Gambar 8. Hasil Diagnosa.

Hasil implementasi aplikasi programsistem pakar penyakit ayam pedaging, seperti pada Tabel 6 :

Tabel 6. Persentase Hasil program

\begin{tabular}{llll}
\hline $\mathrm{N}$ & Name of disease & Certaint & Fuzz \\
\hline
\end{tabular}




\begin{tabular}{clcc}
\hline o. & & $\begin{array}{c}\mathrm{y} \\
\text { Factor } \\
(\%)\end{array}$ & $\begin{array}{c}\mathrm{y} \\
\mathrm{Max} \\
(\%)\end{array}$ \\
\hline 1 & $\begin{array}{l}\text { Snoring Disease (Chronic } \\
\text { Respiratory Disease (CDR)) }\end{array}$ & $96 \%$ & $80 \%$ \\
2 & $\begin{array}{l}\text { Chalk Defecation (Pullorum } \\
\text { Disease) }\end{array}$ & $96 \%$ & $80 \%$ \\
3 & $\begin{array}{l}\text { Gumboro Disease } \\
\text { Tetelo disease (NewCastle }\end{array}$ & $96 \%$ & $80 \%$ \\
& $\begin{array}{l}\text { Disease) } \\
5\end{array}$ & $\begin{array}{l}\text { Snot's disease (Coryza) } \\
6\end{array}$ & $98 \%$ \\
$\begin{array}{l}\text { Chicken Typhus } \\
\text { (Fowl Typhoid) }\end{array}$ & $96 \%$ & $85 \%$ \\
7 & $\begin{array}{l}\text { Intestinal tract disease } \\
\text { (Coccidiosis) }\end{array}$ & $99 \%$ & $90 \%$ \\
8 & $\begin{array}{l}\text { Chicken Cholera Disease } \\
\text { (Fowl Cholera) }\end{array}$ & $96 \%$ & $80 \%$ \\
\hline
\end{tabular}

\section{IV.KESIMPULAN}

Dari hasil penelitian bahwa metode Forward Chaining digunakan untuk pengambilan kesimpulan, sedangkan Metode Fuzzy Max diidapat hasil menunjukkan keakuratan $80 \%$ - 90\% untuk semua jenis penyakit dan Certainty Factor menunjukkan 96\% - 99\% untuk semua jenis penyakit.

\section{DAFTAR PUSTAKA}

[1] I. A. Alshawwa, M. Elkahlout, H. Q. El-mashharawi, and S. S. Abunaser, "An Expert System for Depression Diagnosis," Int. J. Acad. Heal. Med. Res., vol. 3, no. 4, pp. 20-27, 2019, [Online]. Available: www.ijeais.org/ijahmr.

[2] F. M. Salman and S. Abu-Naser, "Expert System for Castor Diseases and Diagnosis," Int. J. Eng. Inf. Syst., vol. 3, no. 3, pp. 1-10, 2019.

[3] B. Herawan Hayadi, A. Bastian, K. Rukun, N. Jalinus, Y. Lizar, and A. Guci, "Expert system in the application of learning models with Forward Chaining Method," Int. J. Eng. Technol., vol. 7, no. 2.29 Special Issue 29, pp. 845-848, 2018, doi:

10.14419/ijet.v7i2.29.14269.

[4] D. T. Pham and M. Castellani, "Action aggregation and defuzzification in Mamdani- type fuzzy systems," Proc. Inst. Mech. Eng. Part C J. Mech. Eng. Sci., vol. 216, no. 7, pp. 747-759, 2002, doi: $10.1243 / 09544060260128797$.

[5] W. U. Setiabudi, E. Sugiharti, and F. Y. Arini, “Expert System Diagnosis Dental Disease Using Certainty Factor Method," Sci. J. Informatics, vol. 4, no. 1, pp. 4350, 2017, doi: 10.15294/sji.v4i1.8463.

[6] B.-A. Andrei, A. Casu-Pop, S.-C. Gheorghe, and C.-A. Boiangiu, "A Study on Using Waterfall and Agile Methods in Software Project Management," J. Inf. Syst. Oper. Manag., no. June, pp. 125-135, 2019, [Online]. Available: http://0- 
search.proquest.com.ditlib.dit.ie.tud

ublin.idm.oclc.org/docview/223782

8314 . accountid=10594.

[7] N. F. Basir et al., "Sweet8Bakery

Booking System," Acta Electron.

Malaysia, vol. 2, no. 2, pp. 14-19,

2018, doi:

10.26480/aem.02.2018.14.19.

[8] A. Details, "Acta Electronica

Malaysia (AEM)," vol. 2, no. 2, pp.
10-13, 2018.

[9] A. Afandi, "Sistem Pakar

Identifikasi Penyakit Ayam

Pedaging," J. Cendikia, vol. 16, no.

1, pp. 58-67, 2018, [Online].

Available:

https://jurnal.dcc.ac.id/index.php/J

C/article/view/65. 